\title{
Currency Hedging for Multinationals under Liquidity Constraints *
}

\author{
Rujing Meng, ${ }^{\dagger}$ Kit Pong Wong ${ }^{\ddagger}$ \\ University of Hong Kong
}

This paper examines the impact of liquidity risk on the behavior of a risk-averse multinational firm (MNF) under exchange rate uncertainty in a two-period dynamic setting. The MNF has operations domiciled in the home country and in a foreign country, each of which produces a single homogeneous good to be sold in the home and foreign markets. To hedge the exchange rate risk, the MNF has access to oneperiod currency futures and option contracts in each period. The MNF is liquidity constrained in that it is obliged to terminate its risk management program in the second period whenever the net loss due to its first-period hedge position exceeds a predetermined threshold level. We show that the MNF optimally sells less (more) and produces more (less) in the foreign (home) country in response to the imposition of the liquidity constraint. We show further that the liquidity constrained MNF optimally uses the currency option contracts in the first period for hedging purposes in general, and opts for a long option position if its utility function is quadratic in particular.

Current date of revision: 11 January 2007

JEL classification: D81; F23; F31

Keywords: Currency hedging; Liquidity constraints; Multinationals

\footnotetext{
*We gratefully acknowledge financial support from a grant provided by the University Grants Committee of the Hong Kong Special Administrative Region, China (Project No. AoE/H-05/99). We would like to thank Donald Lien, Ike Mathur (the editor), and an anonymous referee for their helpful comments and suggestions. The usual disclaimer applies.

${ }^{\dagger}$ School of Economics and Finance, University of Hong Kong, Pokfulam Road, Hong Kong. Tel.: 852-2859-1048, fax: 852-2548-1152, e-mail address: meng@econ.hku.hk (R. Meng).

$\ddagger$ Corresponding author. School of Economics and Finance, University of Hong Kong, Pokfulam Road, Hong Kong. Tel.: 852-2859-1044, fax: 852-2548-1152, e-mail address: kpwong@econ.hku.hk (K. P. Wong).
} 


\title{
Currency hedging for multinationals under liquidity constraints
}

\author{
Rujing Meng, Kit Pong Wong * \\ School of Economics and Finance, University of Hong Kong, Pokfulam Road, Hong Kong
}

\begin{abstract}
This paper examines the impact of liquidity risk on the behavior of a risk-averse multinational firm (MNF) under exchange rate uncertainty in a two-period dynamic setting. The MNF has operations domiciled in the home country and in a foreign country, each of which produces a single homogeneous good to be sold in the home and foreign markets. To hedge the exchange rate risk, the MNF has access to one-period currency futures and option contracts in each period. The MNF is liquidity constrained in that it is obliged to terminate its risk management program in the second period whenever the net loss due to its first-period hedge position exceeds a predetermined threshold level. We show that the MNF optimally sells less (more) and produces more (less) in the foreign (home) country in response to the imposition of the liquidity constraint. We show further that the liquidity constrained MNF optimally uses the currency option contracts in the first period for hedging purposes in general, and opts for a long option position if its utility function is quadratic in particular.
\end{abstract}

JEL classification: D81; F23; F31

Keywords: Currency hedging; Liquidity constraints; Multinationals

\section{Introduction}

Multinational firms (MNFs) should take liquidity risk seriously when devising their risk management strategies. ${ }^{1}$ Failing to comply may oblige even firms that are technically solvent to go bankrupt. A prominent example that vividly illustrates

\footnotetext{
*Corresponding author. Tel.: +852 2859 1044; fax: +852 25481152.

E-mail address: kpwong@econ.hku.hk (K.P. Wong).

${ }^{1}$ According to the Committee on Payment and Settlement Systems (1998), liquidity risk is one of the risks that users of derivatives and other financial contracts must take into account.
} 
such a detrimental consequence of liquidity risk is the case of Metallgesellschaft A. G. (MG), the fourteenth largest industrial firm in Germany.

In 1993, MG's U.S. subsidiary, MG Refining and Marketing, Inc. (MGRM), offered its customers fixed prices on oil and refined oil products up to 10 years into the future as a marketing device. To hedge its exposure to oil prices, MGRM took on large positions in energy derivatives, primarily in oil futures. When oil prices plummeted in that year, MGRM was unable to meet its variation margin payments due to the denial of credit from four major European banks .2 MGRM's liquidity problems resulted in a $\$ 2.4$ billion rescue package coupled with a premature liquidation of its hedge positions en masse so as to keep MG from going bankrupt (Culp and Miller, 1995).

The purpose of this paper is to examine the impact of liquidity risk on the behavior of MNFs facing exchange rate uncertainty in general, and on the hedging role of currency options in particular. To this end, we develop a two-period model of a risk-averse MNF that has operations domiciled in the home country and in a foreign country. Each of these two operations produces a single homogeneous good to be sold in the home and foreign markets. The MNF has access to one-period currency futures and option contracts in each period for hedging purposes. We impose a liquidity constraint on the MNF in that the MNF is forced to terminate its risk management program in the second period whenever the net loss due to its first-period hedge position exceeds a predetermined threshold level. The liquidity constraint as such truncates the MNF's payoff profile. This truncation plays a pivotal role in shaping the MNF's optimal production and hedging decisions.

\footnotetext{
${ }^{2}$ Culp and Hanke (1994) report that "four major European banks called in their outstanding loans to MGRM when its problems became public in December 1993. Those loans, which the banks had previously rolled over each month, denied MGRM much needed cash to finance its variation margin payments and exacerbated its liquidity problems."
} 
When the liquidity constraint is absent, the well-known separation and full-hedging theorems in the literature on MNFs under exchange rate uncertainty apply (see, e.g., Adam-Müller, 1997; Broll and Zilcha, 1992; Katz and Paroush, 1979; Kawai and Zilcha, 1986; Wong, 2003a, 2003b, 2006). The separation theorem states that the MNF's production decision depends neither on its risk attitude nor on the underlying exchange rate uncertainty. The full-hedging theorem states that the MNF should completely eliminate its exchange rate risk exposure by adopting a full-hedge via the unbiased currency futures contracts only. A corollary of the full-hedging theorem is that the liquidity unconstrained MNF does not use the currency option contracts for hedging purposes, thereby ruling out any hedging role of options.

In the presence of the liquidity constraint, the MNF is obliged to terminate its risk management program in the second period should the net loss due to its firstperiod hedge position exceed the predetermined threshold level. The MNF's sales in the foreign market as such are embedded with residual exchange rate risk that cannot be hedged via the unbiased currency futures and option contracts. We show that the MNF demands a positive risk premium on its foreign sales. This creates a wedge between the marginal revenues in the home and foreign markets. In response to the imposition of the liquidity constraint, the MNF optimally sells less (more) and produces more (less) in the foreign (home) country, in accord with the findings of Broll and Zilcha (1992) and Lien and Wong (2005). These adjustments in sales and outputs result in a lower expected global domestic currency profit accrued to and a lower expected utility level attainable by the MNF, as compared to those in the absence of the liquidity constraint.

We show further that the liquidity constrained MNF optimally uses the currency option contracts in the first period for hedging purposes in general, and opts for a long 
option position if its utility function is quadratic in particular. Since the liquidity constraint truncates the MNF's payoff profile, the MNF finds the long option position particularly suitable for its hedging need. Moreover, we show that the MNF underhedges its exchange rate risk exposure so as to strike a balance between the extent of the exchange rate risk and that of the liquidity risk. These findings are consistent with the prevalent use of options (Bodnar, Hayt, and Marston, 1998) and the normal practice of partial hedging (Tufano, 1996; Bodnar, Hayt, and Marston, 1998) by non-financial firms.

The rest of this paper is organized as follows. Section 2 delineates a two-period model of a risk-averse MNF facing both exchange rate uncertainty and liquidity risk. The MNF has access to one-period currency futures and option contracts in each period for hedging purposes. Section 3 characterizes the solution to the model. Section 4 examines the effect of the liquidity constraint on the MNF's optimal production and sales decisions. Section 5 derives the MNF's optimal hedge position in the first period and establishes the hedging role of currency options. Section 6 offers a numerical example to quantify the impact of the liquidity constraint on the behavior of the MNF. The final section concludes.

\section{The model}

Consider a two-period, three-date (indexed by $t=0,1$, and 2) model of a multinational firm (MNF) that has operations domiciled in the home country and in a foreign country. At $t=0$, interest rates in both periods are known with certainty. To simplify notation, we henceforth suppress the interest factors by compounding all cash flows to their future values at $t=2$. 
The MNF's home operation produces a single homogeneous good, $x$, according to a cost function, $c_{x}(x)$, denominated in the domestic currency. We assume that $c_{x}(0) \geq 0, c_{x}^{\prime}(x)>0$, and $c_{x}^{\prime \prime}(x)>0$ to reflect the fact that the MNF's production technology exhibits decreasing returns to scale. At $t=2$, the MNF sells $x_{h}$ and $x_{f}$ units of the good, $x$, in the home and foreign countries, respectively. The sales in the home market generate a revenue function, $r_{x}\left(x_{h}\right)$, denominated in the domestic currency, whereas the sales in the foreign market generate a revenue function, $R_{x}\left(x_{f}\right)$, denominated in the foreign currency. We assume that $r_{x}\left(x_{h}\right)$ and $R_{x}\left(x_{f}\right)$ are strictly increasing and concave to capture the idea that the MNF is likely to enjoy some monopoly power in the home and foreign markets.

The MNF's foreign operation produces another single homogeneous good, $y$, according to a cost function, $c_{y}(y)$, denominated in the foreign currency, where $c_{y}(0) \geq$ $0, c_{y}^{\prime}(y)>0$, and $c_{y}^{\prime \prime}(y)>0$. We assume that the two homogeneous goods, $x$ and $y$, are independent of each other. ${ }^{3}$ At $t=2$, the MNF sells $y_{h}$ and $y_{f}$ units of the good, $y$, in the home and foreign countries, respectively. The sales in the home market generate a revenue function, $r_{y}\left(y_{h}\right)$, denominated in the domestic currency, whereas the sales in the foreign market generate a revenue function, $R_{y}\left(y_{f}\right)$, denominated in the foreign currency. The revenue functions, $r_{y}\left(y_{h}\right)$ and $R_{y}\left(y_{f}\right)$, are strictly increasing and concave.

The spot exchange rate at date $t(t=1$ and 2$)$, denoted by $\tilde{e}_{t}$ and expressed in units of the domestic currency against the foreign currency, is not known at $t=0 .{ }^{4}$ We assume that the spot exchange rates follow a random walk so that $\tilde{e}_{t}=e_{t-1}+\tilde{\varepsilon}_{t}$,

\footnotetext{
${ }^{3}$ In an earlier version of this paper, we have considered an alternative case that the MNF's home and foreign operations produce the same homogeneous good. None of the qualitative results are affected except that we would have one-way trade between the home and foreign operations rather than two-way trade as in the current model.

${ }^{4}$ Throughout the paper, random variables have a tilde $(\sim)$ while their realizations do not.
} 
where $\tilde{\varepsilon}_{1}$ and $\tilde{\varepsilon}_{2}$ are two zero-mean random variables independent of each other. To hedge the exchange rate risk, the MNF can trade one-period currency futures and call option contracts at the beginning of each period. ${ }^{5}$ The MNF is a price taker in the currency futures and options markets.

At $t=0$, the MNF sells (purchases if negative) $h_{0}$ units of the first-period currency futures contracts at the predetermined futures exchange rate, $f_{0}$. At the same time, the MNF writes (buys if negative) $z_{0}$ units of the first-period currency call options with the strike price, $s_{0}$, and at the predetermined option premium, $p_{0}$. Conditional on the realized value of the spot exchange rate at $t=1$, the MNF enjoys a net gain (or suffers a net loss if negative) of $\left(f_{0}-e_{1}\right) h_{0}-\max \left(e_{1}-s_{0}, 0\right) z_{0}$ from its first-period hedge position, $\left(h_{0}, z_{0}\right)$. As in Wong (2004) and Lien and Wong (2005), the MNF is liquidity constrained in that it is obliged to terminate its risk management program whenever the net loss incurred at $t=1$ exceeds a prespecified threshold level, $k$. That is, if $\left(e_{1}-f_{0}\right) h_{0}+\max \left(e_{1}-s_{0}, 0\right) z_{0}>k$, the MNF's random global profit at $t=2$, denominated in the domestic currency, is given by

$$
\begin{aligned}
\tilde{\pi}_{\ell}= & r_{x}\left(x_{h}\right)+r_{y}\left(y_{h}\right)-c_{x}\left(x_{h}+x_{f}\right)+\left(e_{1}+\tilde{\varepsilon}_{2}\right)\left[R_{x}\left(x_{f}\right)+R_{y}\left(y_{f}\right)-c_{y}\left(y_{h}+y_{f}\right)\right] \\
& +\left(f_{0}-e_{1}\right) h_{0}+\left[p_{0}-\max \left(e_{1}-s_{0}, 0\right)\right] z_{0}
\end{aligned}
$$

since $\tilde{e}_{2}=e_{1}+\tilde{\varepsilon}_{2}$.

At $t=1$, if the net loss from its first-period hedge position, $\left(h_{0}, z_{0}\right)$, is below the prespecified threshold level, $k$, the MNF continues its risk management program in the second period. In this case, the MNF sells (purchases if negative) $h_{1}$ units of the

\footnotetext{
${ }^{5}$ We do not consider currency put option contracts because they are redundant in that they can be readily replicated by combinations of currency futures and call option contracts (Sercu and Uppal, 1995).
} 
second-period currency futures contracts at the then prevailing futures exchange rate, $f_{1}$, and writes (buys if negative) $z_{1}$ units of the second-period currency call options with the strike price, $s_{1}$, and at the then prevailing option premium, $p_{1}$. The MNF expects the second-period currency futures and call option contracts to be unbiased in that $f_{1}=e_{1}$ and $p_{1}$ is set equal to the expected value of $\max \left(e_{1}+\tilde{\varepsilon}_{2}-s_{1}, 0\right)$. Thus, if $\left(e_{1}-f_{0}\right) h_{0}+\max \left(e_{1}-s_{0}, 0\right) z_{0} \leq k$, the MNF's random global domestic currency profit at $t=2$ is given by

$$
\tilde{\pi}_{c}=\tilde{\pi}_{\ell}+\left(f_{1}-e_{1}-\tilde{\varepsilon}_{2}\right) h_{1}+\left[p_{1}-\max \left(e_{1}+\tilde{\varepsilon}_{2}-s_{1}, 0\right)\right] z_{1},
$$

where $\tilde{\pi}_{\ell}$ is defined in Eq. (1).

The MNF possesses a von Neumann-Morgenstern utility function, $u(\pi)$, defined over its global domestic currency profit at $t=2, \pi$, with $u^{\prime}(\pi)>0$ and $u^{\prime \prime}(\pi)<0$, indicating the presence of risk aversion. ${ }^{6}$ The MNF's multi-period decision problem can be described in the following recursive manner. At $t=1$, if the net loss from its first-period hedge position, $\left(h_{0}, z_{0}\right)$, does not exceed the threshold level, $k$, the MNF is allowed to choose its second-period hedge position, $\left(h_{1}, z_{1}\right)$, so as to maximize the expected utility of its random global domestic currency profit at $t=2$, which is given by Eq. (2). At $t=0$, anticipating the liquidity constraint at $t=1$ and its second-period optimal hedge position, $\left(h_{1}^{*}, z_{1}^{*}\right)$, the MNF chooses the levels of sales in the home and foreign markets, $x_{h}, y_{h}, x_{f}$, and $y_{f}$, and selects the first-period hedge position, $\left(h_{0}, z_{0}\right)$, so as to maximize the expected utility of its random global domestic currency profit at $t=2$, which is given by Eqs. (1) and (2).

\footnotetext{
${ }^{6}$ If the MNF is risk neutral, currency hedging adds no value to the MNF. The assumption of risk aversion can be justified by the prevalence of corporate taxes, costs of financial distress, or capital market imperfections (see Stulz, 1996).
} 


\section{Solution to the model}

As usual, the MNF's multi-period decision problem is solved by using backward induction. At $t=1$, if $\left(e_{1}-f_{0}\right) h_{0}+\max \left(e_{1}-s_{0}, 0\right) z_{0}>k$, the MNF is obliged to terminate its risk management program and thereby no further hedging decisions can be made. On the other hand, if $\left(e_{1}-f_{0}\right) h_{0}+\max \left(e_{1}-s_{0}, 0\right) z_{0} \leq k$, the MNF is allowed to choose its second-period hedge position, $\left(h_{1}, z_{1}\right)$, so as to maximize the expected utility of its random global domestic currency profit at $t=2$ :

$$
\max _{h_{1}, z_{1}} \mathrm{E}_{2}\left[u\left(\tilde{\pi}_{c}\right)\right]
$$

where $\mathrm{E}_{2}(\cdot)$ is the expectation operator with respect to the cumulative distribution function of $\tilde{\varepsilon}_{2}$, and $\tilde{\pi}_{c}$ is defined in Eq. (2). The first-order conditions for program (3) are given $\mathrm{by}^{7}$

$$
\mathrm{E}_{2}\left[u^{\prime}\left(\tilde{\pi}_{c}^{*}\right)\left(f_{1}-e_{1}-\tilde{\varepsilon}_{2}\right)\right]=0,
$$

and

$$
\mathrm{E}_{2}\left\{u^{\prime}\left(\tilde{\pi}_{c}^{*}\right)\left[p_{1}-\max \left(e_{1}+\tilde{\varepsilon}_{2}-s_{1}, 0\right)\right]\right\}=0,
$$

where an asterisk $\left(^{*}\right)$ indicates an optimal level.

If $h_{1}=R_{x}\left(x_{f}\right)+R_{y}\left(y_{f}\right)-c_{y}\left(y_{h}+y_{f}\right)$ and $z_{1}=0$, Eq. (2) implies that the MNF's global domestic currency profit at $t=2$ becomes

$$
\begin{aligned}
& r_{x}\left(x_{h}\right)+r_{y}\left(y_{h}\right)-c_{h}\left(x_{h}+x_{f}\right)+f_{1}\left[R_{x}\left(x_{f}\right)+R_{y}\left(y_{f}\right)-c_{y}\left(y_{h}+y_{f}\right)\right] \\
& +\left(f_{0}-e_{1}\right) h_{0}+\left[p_{0}-\max \left(e_{1}-s_{0}, 0\right)\right] z_{0},
\end{aligned}
$$

\footnotetext{
${ }^{7}$ The second-order conditions for program (3) are satisfied given risk aversion.
} 
which is non-stochastic. Since $f_{1}=e_{1}, \mathrm{E}_{2}\left(\tilde{\varepsilon}_{2}\right)=0$, and $p_{1}=\mathrm{E}_{2}\left[\max \left(e_{1}+\tilde{\varepsilon}_{2}-s_{1}, 0\right)\right]$, it follows that $h_{1}^{*}=R_{x}\left(x_{f}\right)+R_{y}\left(y_{f}\right)-c_{y}\left(y_{h}+y_{f}\right)$ and $z_{1}^{*}=0$ indeed solve Eqs. (4) and (5) simultaneously. When the MNF can continue its risk management program in the second period, there are no more liquidity constraints. In this case, the fullhedging theorem in the literature on MNFs under exchange rate uncertainty applies (see, e.g., Adam-Müller, 1997; Broll and Zilcha, 1992; Katz and Paroush, 1979; Kawai and Zilcha, 1986; Wong, 2003a, 2003b, 2006). As such, the MNF finds it optimal to completely eliminate its exchange rate risk exposure by adopting a full-hedge via the unbiased second-period currency futures contracts, i.e., $h_{1}^{*}=R_{x}\left(x_{f}\right)+R_{y}\left(y_{f}\right)-$ $c_{y}\left(y_{h}+y_{f}\right)$. There is no hedging role to be played by the unbiased second-period currency call option contracts, i.e., $z_{1}^{*}=0$.

Note that $e_{1}=e_{0}+\varepsilon_{1}$. If $\left(e_{0}+\varepsilon_{1}-f_{0}\right) h_{0}+\max \left(e_{0}+\varepsilon_{1}-s_{0}, 0\right) z_{0} \leq k$, i.e., if $\varepsilon_{1} \leq\left(k+f_{0} h_{0}+s_{0} z_{0}\right) /\left(h_{0}+z_{0}\right)-e_{0}$, the MNF anticipates that its optimal secondperiod hedge position is $\left(h_{1}^{*}, z_{1}^{*}\right)$ as characterized above so that its random global domestic currency profit at $t=2$ is given by

$$
\begin{aligned}
\pi_{c}\left(\varepsilon_{1}\right)= & r_{x}\left(x_{h}\right)+r_{y}\left(y_{h}\right)-c_{x}\left(x_{h}+x_{f}\right)+\left(e_{0}+\varepsilon_{1}\right)\left[R_{x}\left(x_{f}\right)+R_{y}\left(y_{f}\right)-c_{y}\left(y_{h}+y_{f}\right)\right] \\
& +\left(f_{0}-e_{0}-\varepsilon_{1}\right) h_{0}+\left[p_{0}-\max \left(e_{0}+\varepsilon_{1}-s_{0}, 0\right)\right] z_{0} .
\end{aligned}
$$

On the other hand, if $\left(e_{0}+\varepsilon_{1}-f_{0}\right) h_{0}+\max \left(e_{0}+\varepsilon_{1}-s_{0}, 0\right) z_{0}>k$, i.e., if $\varepsilon_{1}>$ $\left(k+f_{0} h_{0}+s_{0} z_{0}\right) /\left(h_{0}+z_{0}\right)-e_{0}$, the MNF is obliged to terminate its risk management program in the second period so that its random global domestic currency profit at $t=2$ becomes

$$
\pi_{\ell}\left(\varepsilon_{1}, \tilde{\varepsilon}_{2}\right)=\pi_{c}\left(\varepsilon_{1}\right)+\tilde{\varepsilon}_{2}\left[R_{x}\left(x_{f}\right)+R_{y}\left(y_{f}\right)-c_{y}\left(y_{h}+y_{f}\right)\right]
$$

where $\pi_{c}\left(\varepsilon_{1}\right)$ is defined in Eq. (6). 
Now, we go back to $t=0$. The MNF's ex-ante decision problem is to choose the levels of sales in the home and foreign operations, $x_{h}, x_{f}, y_{h}$, and $y_{f}$, and selects the first-period hedge position, $\left(h_{0}, z_{0}\right)$, so as to maximize the expected utility of its random global domestic currency profit at $t=2$ :

$$
\begin{array}{rl}
\max _{x_{h}, x_{f}, y_{h}, y_{f}, h_{0}, z_{0}} \int_{\underline{\varepsilon}_{1}}^{\frac{k+f_{0} h_{0}+s_{0} z_{0}}{h_{0}+z_{0}}-e_{0}} & u\left[\pi_{c}\left(\varepsilon_{1}\right)\right] \mathrm{d} F\left(\varepsilon_{1}\right) \\
+ & \int_{\frac{k+f_{0} h_{0}+s_{0} z_{0}}{h_{0}+z_{0}}-e_{0}}^{\bar{\varepsilon}_{1}} \mathrm{E}_{2}\left\{u\left[\pi_{\ell}\left(\varepsilon_{1}, \tilde{\varepsilon}_{2}\right)\right]\right\} \mathrm{d} F\left(\varepsilon_{1}\right),
\end{array}
$$

where $F\left(\varepsilon_{1}\right)$ is the cumulative distribution function of $\tilde{\varepsilon}_{1}$ over support $\left[\underline{\varepsilon}_{1}, \bar{\varepsilon}_{1}\right]$, with $-\infty \leq \underline{\varepsilon}_{1}<0<\bar{\varepsilon}_{1} \leq \infty$, and $\pi_{c}\left(\varepsilon_{1}\right)$ and $\pi_{\ell}\left(\varepsilon_{1}, \tilde{\varepsilon}_{2}\right)$ are defined in Eqs. (6) and (7), respectively. The first-order conditions for program (8) are given in Appendix A. ${ }^{8}$

\section{Optimal production and sales decisions}

In this section, we examine the optimal production and sales decisions of the MNF in the presence of the liquidity constraint. From the first-order conditions for program (8), we can derive the following system of equations: ${ }^{9}$

$$
\begin{aligned}
& r_{x}^{\prime}\left(x_{h}^{*}\right)=c_{x}^{\prime}\left(x_{h}^{*}+x_{f}^{*}\right), \\
& \left(f_{0}-\theta\right) R_{x}^{\prime}\left(x_{f}^{*}\right)=c_{x}^{\prime}\left(x_{h}^{*}+x_{f}^{*}\right), \\
& r_{y}^{\prime}\left(y_{h}^{*}\right)=\left(f_{0}-\theta\right) c_{y}^{\prime}\left(y_{h}^{*}+y_{f}^{*}\right),
\end{aligned}
$$

and

$$
R_{y}^{\prime}\left(y_{f}^{*}\right)=c_{y}^{\prime}\left(y_{h}^{*}+y_{f}^{*}\right)
$$

\footnotetext{
${ }^{8}$ The second-order conditions for program (8) are satisfied given risk aversion and the assumed properties of $r_{x}\left(x_{h}\right), r_{y}\left(y_{h}\right), R_{x}\left(x_{f}\right), R_{y}\left(y_{f}\right), c_{x}(x)$, and $c_{y}(y)$.

${ }^{9}$ See Appendix A for the derivation.
} 
where an asterisk $\left(^{*}\right)$ indicates an optimal level, and $\theta>0$ is defined in Eq. (A.9) in Appendix A.

As a benchmark, suppose that the MNF does not encounter the liquidity constraint. In this case, Eqs. (9) to (12) reduce to ${ }^{10}$

$$
\begin{aligned}
& r_{x}^{\prime}\left(x_{h}^{0}\right)=c_{x}^{\prime}\left(x_{h}^{0}+x_{f}^{0}\right), \\
& f_{0} R_{x}^{\prime}\left(x_{f}^{0}\right)=c_{x}^{\prime}\left(x_{h}^{0}+x_{f}^{0}\right), \\
& r_{y}^{\prime}\left(y_{h}^{0}\right)=f_{0} c_{y}^{\prime}\left(y_{h}^{0}+y_{f}^{0}\right),
\end{aligned}
$$

and

$$
R_{y}^{\prime}\left(y_{f}^{0}\right)=c_{y}^{\prime}\left(y_{h}^{0}+y_{f}^{0}\right)
$$

where a nought $\left(^{0}\right)$ indicates an optimal level in this benchmark case. In the absence of the liquidity constraint, the MNF's random global domestic currency profit at $t=2$ is given by Eq. (2) only. The MNF could have completely eliminated its exposure to the exchange rate risk had it chosen $h_{0}=R_{x}\left(x_{f}\right)+R_{y}\left(y_{f}\right)-c_{y}\left(y_{h}+y_{f}\right)$ and $z_{0}=0$ within its own discretion. Alternatively put, the degree of exchange rate risk exposure to be assumed by the MNF should be totally unrelated to its production and sales decisions. The optimal levels of sales in the home and foreign markets are then chosen to maximize $r_{x}\left(x_{h}\right)+r_{y}\left(y_{h}\right)-c_{x}\left(x_{h}+x_{f}\right)+f_{0}\left[R_{x}\left(x_{f}\right)+R_{y}\left(y_{f}\right)-c_{y}\left(y_{h}+y_{f}\right)\right]$, thereby yielding Eqs. (13) to (16). Eq. (13) states that the MNF equates the marginal cost of the good produced in the home operation to the marginal revenue of the good in the home market. Eqs. (13) and (14) imply that the marginal revenues of the good

\footnotetext{
${ }^{10}$ The benchmark case is tantamount to setting $k=\infty$. From Eq. (A.9) in Appendix A, it is evident that $\theta=0$ when $k=\infty$.
} 
produced in the home operation, denominated in the domestic currency, are equalized in the home and foreign markets, where the exchange rate is locked in at the initial futures exchange rate, $f_{0}$. Likewise, Eqs. (15) and (16) imply similar optimality conditions for the good produced in the foreign operation. ${ }^{11}$

Comparing the set of optimality conditions with the liquidity constraint, Eqs. (9) to (12), to that without the liquidity constraint, Eqs. (13) to (16), yields the following proposition. $^{12}$

Proposition 1. If the risk-averse MNF has access to the currency futures and options markets for hedging purposes in each period, then imposing the liquidity constraint on the MNF induces (i) greater sales of both goods in the home market, i.e., $x_{h}^{*}>x_{h}^{0}$ and $y_{h}^{*}>y_{h}^{0}$, (ii) lower sales of both goods in the foreign market, i.e., $x_{f}^{*}<x_{f}^{0}$ and $y_{f}^{*}<y_{f}^{0}$, (iii) lower output in the home operation, i.e., $x_{h}^{*}+x_{f}^{*}<x_{h}^{0}+x_{f}^{0}$, and (iv) higher output in the foreign operation, i.e., $y_{h}^{*}+y_{f}^{*}>y_{h}^{0}+y_{f}^{0}$.

To see the intuition of Proposition 1, we refer to Eqs. (6) and (7). In the presence of the liquidity constraint, setting $h_{0}=R_{x}\left(x_{f}\right)+R_{y}\left(y_{f}\right)-c_{y}\left(y_{h}+y_{f}\right)$ and $z_{0}=0$ cannot eliminate all the exchange rate risk due to the residual risk, $\tilde{\varepsilon}_{2}\left[R_{x}\left(x_{f}\right)+R_{y}\left(y_{f}\right)-\right.$ $\left.c_{y}\left(y_{h}+y_{f}\right)\right]$, arising from the termination of the risk management program at $t=1$, as is evident from Eq. (7). Such residual risk, however, can be controlled by varying the levels of sales in the home and foreign markets. Eq. (9) states that it remains optimal for the MNF to equate the marginal cost of the good produced in the home operation to the marginal revenue of the good in the home market. Eqs. (9) and

\footnotetext{
${ }^{11}$ These results are analogous to the celebrated separation theorem in the literature on MNFs under exchange rate uncertainty (see, e.g., Adam-Müller, 1997; Broll and Zilcha, 1992; Katz and Paroush, 1979; Kawai and Zilcha, 1986; Wong, 2003a, 2003b, 2006).

${ }^{12}$ All proofs of propositions are given in Appendix A.
} 
(10), however, imply that the marginal revenue of the good produced in the home operation is strictly smaller in the home market than in the foreign market, where the latter is denominated in the domestic currency with the exchange rate locked in at the initial futures exchange rate, $f_{0}$. Since the sales in the foreign market are embedded with some exchange rate risk that cannot be eliminated due to the presence of the liquidity constraint, the MNF has to demand a risk premium to compensate for its foreign sales. The wedge between the two marginal revenues in the home and foreign markets is de facto the risk premium required by the MNF. Similar arguments apply to the good produced in the foreign operation. The MNF as such sells less (more) and produces more (less) in the foreign (home) country. These results are in line with the findings of Broll and Zilcha (1992) and Lien and Wong (2005). ${ }^{13}$

\section{Optimal hedging decisions}

In this section, we examine the optimal hedging decisions of the MNF in the presence of the liquidity constraint. We are particularly interested in scrutinizing the hedging role of the first-period currency call options. To this end, we impose an additional assumption that the first-period currency futures and call option contracts are both unbiased in that $f_{0}=e_{0}$ and $p_{0}$ is set equal to the expected value of $\max \left(e_{0}+\tilde{\varepsilon}_{1}-s_{0}, 0\right) \cdot{ }^{14}$ We say that the first-period currency call options are in the money, at the money, or out of the money if, and only if, $s_{0}$ is less than, equal to, or greater than $e_{0}$, respectively.

\footnotetext{
${ }^{13}$ Lien and Wong (2005) derive similar results when the MNF is restricted to use unbiased twoperiod currency futures contracts that are marked to market in each period. Since the hedging environment is more incomplete in Lien and Wong (2005), risk aversion alone does not suffice to yield the desired results and additional condition of prudence (Kimball, 1990, 1993) is called for.

${ }^{14}$ We introduce this unbiasedness assumption so as to focus on the MNF's hedging motive (vis-à-vis its speculative motive). If there are many risk-neutral speculators populated in the currency futures and option markets, the unbiasedness of the futures and option prices is an immediate consequence of no arbitrage opportunities.
} 
In the benchmark case wherein the liquidity constraint is absent, it is evident that the full-hedging theorem holds. Specifically, the MNF's optimal first-period hedge position, $\left(h_{0}^{0}, z_{0}^{0}\right)$, satisfies that $h_{0}^{0}=R_{x}\left(x_{f}^{0}\right)+R_{y}\left(y_{f}^{0}\right)-c_{y}\left(y_{h}^{0}+y_{f}^{0}\right)$ and $z_{0}^{0}=0$, which completely eliminates the MNF's exchange rate risk exposure. Thus, the liquidity unconstrained MNF uses no currency options for hedging purposes.

In the presence of the liquidity constraint, the full-hedging theorem in general does not hold. To see this, it suffices to restrict our attention to the case wherein the MNF's utility function, $u(\pi)$, takes on the following quadratic form:

$$
u(\pi)=u(0)+a \pi-\frac{b}{2} \pi^{2}
$$

where $a$ and $b$ are positive constants such that $u^{\prime}(\pi)=a-b \pi>0$ for all relevant values of $\pi$. In this case, the first-order conditions for program (8) imply the following system of equations: ${ }^{15}$

$$
-\operatorname{Cov}_{1}\left[a-b \pi_{c}^{*}\left(\tilde{\varepsilon}_{1}\right), \tilde{\varepsilon}_{1}\right]-b \psi_{1}=0
$$

and

$$
-\operatorname{Cov}_{1}\left[a-b \pi_{c}^{*}\left(\tilde{\varepsilon}_{1}\right), \max \left(e_{0}+\tilde{\varepsilon}_{1}-s_{0}, 0\right)\right]-b \psi_{2}=0
$$

where $\operatorname{Cov}_{1}(\cdot, \cdot)$ is the covariance operator with respect to $F\left(\varepsilon_{1}\right), \varepsilon_{1}^{*}=\left(k+e_{0} h_{0}^{*}+\right.$ $\left.s_{0} z_{0}^{*}\right) /\left(h_{0}^{*}+z_{0}^{*}\right)-e_{0}$,

$$
\psi_{1}=\frac{1}{2} \mathrm{E}_{2}\left(\tilde{\varepsilon}_{2}^{2}\right)\left[R_{x}\left(x_{f}^{*}\right)+R_{y}\left(y_{f}^{*}\right)-c_{y}\left(y_{h}^{*}+y_{f}^{*}\right)\right]^{2} F^{\prime}\left(\varepsilon_{1}^{*}\right) \frac{k+\left(s_{0}-e_{0}\right) z_{0}^{*}}{\left(h_{0}^{*}+z_{0}^{*}\right)^{2}}>0 .
$$

\footnotetext{
${ }^{15}$ From Eqs. (6) and (7), we have $\pi_{c}^{*}\left(\varepsilon_{1}\right)=\mathrm{E}_{2}\left[\pi_{\ell}^{*}\left(\varepsilon_{1}, \tilde{\varepsilon}_{2}\right)\right]$ for all $\varepsilon_{1} \in\left[\underline{\varepsilon}_{1}, \bar{\varepsilon}_{1}\right]$. Since $u(\pi)$ is defined in Eq. (17), we have $u^{\prime}\left[\pi_{c}^{*}\left(\varepsilon_{1}\right)\right]=\mathrm{E}_{2}\left\{u^{\prime}\left[\pi_{\ell}^{*}\left(\varepsilon_{1}, \tilde{\varepsilon}_{2}\right)\right]\right\}=a-b \pi_{c}^{*}\left(\varepsilon_{1}\right)$ for all $\varepsilon_{1} \in\left[\underline{\varepsilon}_{1}, \bar{\varepsilon}_{1}\right]$. Thus, Eqs. (A.5) and (A.6) in Appendix A reduce to Eqs. (18) and (19), respectively.
} 
and

$$
\psi_{2}=\frac{1}{2} \mathrm{E}_{2}\left(\tilde{\varepsilon}_{2}^{2}\right)\left[R_{x}\left(x_{f}^{*}\right)+R_{y}\left(y_{f}^{*}\right)-c_{y}\left(y_{h}^{*}+y_{f}^{*}\right)\right]^{2} F^{\prime}\left(\varepsilon_{1}^{*}\right) \frac{k+\left(e_{0}-s_{0}\right) h_{0}^{*}}{\left(h_{0}^{*}+z_{0}^{*}\right)^{2}}>0 .
$$

Using Eq. (6), we can write Eqs. (18) and (19) as

$$
\begin{aligned}
& \operatorname{Var}_{1}\left(\tilde{\varepsilon}_{1}\right)\left[R_{x}\left(x_{f}^{*}\right)+R_{y}\left(y_{f}^{*}\right)-c_{y}\left(y_{h}^{*}+y_{f}^{*}\right)-h_{0}^{*}\right] \\
& -\operatorname{Cov}_{1}\left[\tilde{\varepsilon}_{1}, \max \left(e_{0}+\tilde{\varepsilon}_{1}-s_{0}, 0\right)\right] z_{0}^{*}=\psi_{1},
\end{aligned}
$$

and

$$
\begin{aligned}
& \operatorname{Cov}_{1}\left[\tilde{\varepsilon}_{1}, \max \left(e_{0}+\tilde{\varepsilon}_{1}-s_{0}, 0\right)\right]\left[R_{x}\left(x_{f}^{*}\right)+R_{y}\left(y_{f}^{*}\right)-c_{y}\left(y_{h}^{*}+y_{f}^{*}\right)-h_{0}^{*}\right] \\
& -\operatorname{Var}_{1}\left[\max \left(e_{0}+\tilde{\varepsilon}_{1}-s_{0}, 0\right)\right] z_{0}^{*}=\psi_{2},
\end{aligned}
$$

where $\operatorname{Var}_{1}(\cdot)$ is the variance operator with respect to $F\left(\varepsilon_{1}\right)$.

Multiplying $\operatorname{Var}_{1}\left[\max \left(e_{0}+\tilde{\varepsilon}_{1}-e_{0}, 0\right)\right]$ to Eq. (22) and $\operatorname{Cov}_{1}\left[\tilde{\varepsilon}_{1}, \max \left(e_{0}+\tilde{\varepsilon}_{1}-s_{0}, 0\right)\right]$ to Eq. (23), and subtracting the resulting two equations yields

$$
\begin{aligned}
h_{0}^{*}= & R_{x}\left(x_{f}^{*}\right)+R_{y}\left(y_{f}^{*}\right)-c_{y}\left(y_{h}^{*}+y_{f}^{*}\right) \\
& +\frac{\psi_{2} \operatorname{Cov}_{1}\left[\tilde{\varepsilon}_{1}, \max \left(e_{0}+\tilde{\varepsilon}_{1}-s_{0}, 0\right)\right]-\psi_{1} \operatorname{Var}_{1}\left[\max \left(e_{0}+\tilde{\varepsilon}_{1}-s_{0}, 0\right)\right]}{\operatorname{Var}_{1}\left(\tilde{\varepsilon}_{1}\right) \operatorname{Var}\left[\max \left(e_{0}+\tilde{\varepsilon}_{1}-s_{0}, 0\right)\right]-\operatorname{Cov}_{1}\left[\tilde{\varepsilon}_{1}, \max \left(e_{0}+\tilde{\varepsilon}_{1}-s_{0}, 0\right)\right]^{2}} .
\end{aligned}
$$

Multiplying $\operatorname{Cov}_{1}\left[\tilde{\varepsilon}_{1}, \max \left(e_{0}+\tilde{\varepsilon}_{1}-s_{0}, 0\right)\right]$ to Eq. (22) and $\operatorname{Var}_{1}\left(\tilde{\varepsilon}_{1}\right)$ to Eq. (23), and subtracting the resulting two equations yields

$$
z_{0}^{*}=\frac{\psi_{1} \operatorname{Cov}_{1}\left[\tilde{\varepsilon}_{1}, \max \left(e_{0}+\tilde{\varepsilon}_{1}-s_{0}, 0\right)\right]-\psi_{2} \operatorname{Var}_{1}\left(\tilde{\varepsilon}_{1}\right)}{\operatorname{Var}_{1}\left(\tilde{\varepsilon}_{1}\right) \operatorname{Var}\left[\max \left(e_{0}+\tilde{\varepsilon}_{1}-s_{0}, 0\right)\right]-\operatorname{Cov}_{1}\left[\tilde{\varepsilon}_{1}, \max \left(e_{0}+\tilde{\varepsilon}_{1}-s_{0}, 0\right)\right]^{2}} .
$$


It is evident from Eqs. (20) and (21) that $\psi_{1}$ and $\psi_{2}$ depend on $h_{0}^{*}$ and $z_{0}^{*}$. Thus, Eqs. (24) and (25) do not give us a closed form solution to $h_{0}^{*}$ and $z_{0}^{*}$.

The following proposition characterizes the MNF's first-period optimal hedge position, $\left(h_{0}^{*}, z_{0}^{*}\right)$.

Proposition 2. Suppose that the liquidity constrained MNF has access to the unbiased one-period currency futures and call option contracts for hedging purposes in each period and has a quadratic utility function. If the first-period currency call options are not too out of the money, then the MNF's optimal first-period hedge position, $\left(h_{0}^{*}, z_{0}^{*}\right)$, satisfies that $h_{0}^{*}>R_{x}\left(x_{f}^{*}\right)+R_{y}\left(y_{f}^{*}\right)-c_{y}\left(y_{h}^{*}+y_{f}^{*}\right), z_{0}^{*}<0$, and $h_{0}^{*}+z_{0}^{*}<R_{x}\left(x_{f}^{*}\right)+R_{y}\left(y_{f}^{*}\right)-c_{y}\left(y_{h}^{*}+y_{f}^{*}\right)$.

The intuition of Proposition 2 is as follows. If the MNF opts for the first-period hedge position with $h_{0}=R_{x}\left(x_{f}\right)+R_{y}\left(y_{f}\right)-c_{y}\left(y_{h}+y_{f}\right)$ and $z_{0}=0$, the MNF faces no exchange rate risk only when its risk management program is continued at $t=1$, which occurs over the interval, $\left[\underline{\varepsilon}_{1}, k / h_{0}\right]$. If the currency call option contracts are not too out of the money (i.e., $s_{0}$ is not sufficiently greater than $e_{0}$ ), the MNF finds it optimal to opt for $z_{0}<0$ in order to further improve the hedging performance. Doing so enlarges the interval from $\left[\underline{\varepsilon}_{1}, k / h_{0}\right]$ to $\left[\underline{\varepsilon}_{1},\left(k+s_{0} z_{0}-e_{0} z_{0}\right) /\left(h_{0}+z_{0}\right)\right]$. In this case, we have $h_{0}+z_{0}<R_{x}\left(x_{f}\right)+R_{y}\left(y_{f}\right)-c_{y}\left(y_{h}+y_{f}\right)$ so that the MNF's global domestic currency profit is low when the realizations of $\tilde{\varepsilon}_{1}$ are small. Being risk averse, the MNF cares more about the states in which its realized global domestic currency profit is low than those states in which its realized global domestic currency profit is high. The risk-averse MNF thus increases its first-period futures position such that $h_{0}>R_{x}\left(x_{f}\right)+R_{y}\left(y_{f}\right)-c_{y}\left(y_{h}+y_{f}\right)$ but $h_{0}+z_{0}<R_{x}\left(x_{f}\right)+R_{y}\left(y_{f}\right)-c_{y}\left(y_{h}+y_{f}\right)$. This hedge position shifts the MNF's global domestic currency profit from the high states 
to the low states, thereby achieving the best hedging performance in the presence of the liquidity constraint.

In the 1998 Wharton survey of financial risk management by US non-financial firms, Bodnar, Hayt, and Marston (1998) report that $68 \%$ of the 200 derivativesusing firms indicated that they had used some form of options within the past 12 months. Also, they find that most companies in the survey do not completely hedge their risk exposures. Tufano (1996) documents that in the gold mining industry only $17 \%$ of firms shed $40 \%$ or more of their price risk. These empirical findings are consistent with the results in Proposition 2. The prevalence of liquidity constraints faced by MNFs is likely to account for the hedging role of currency options and the optimality of under-hedging by these firms.

\section{A numerical example}

In this section, we construct a numerical example to quantify the impact of the liquidity constraint on the behavior of the MNF. To this end, suppose that the MNF has the utility function: $u(\pi)=10 \pi-0.2 \pi^{2}$, the cost functions: $c_{x}(x)=0.5 x^{2}$ and $c_{y}(y)=0.5 y^{2}$, and the revenue functions: $r_{x}\left(x_{h}\right)=10 \sqrt{x_{h}}, r_{y}\left(y_{h}\right)=10 \sqrt{y_{h}}$, $R_{x}\left(x_{f}\right)=10 \sqrt{x_{f}}$, and $R_{y}\left(y_{f}\right)=10 \sqrt{y_{f}}$. Assume that $\tilde{\varepsilon}_{1}$ and $\tilde{\varepsilon}_{2}$ are two standard normal variates. Furthermore, assume that the one-period currency futures and call option contracts are unbiased in each period. We set $s_{0}=e_{0}=1$ and $k=5$.

In the absence of the liquidity constraint, we have $x_{h}^{0}=x_{f}^{0}=y_{h}^{0}=y_{f}^{0}=1.84$. In the presence of the liquidity constraint, we have $x_{h}^{*}=2.24, x_{f}^{*}=1.10, y_{h}^{*}=2.84$, and $y_{f}^{*}=1.39$, so that the output in the home operation drops by $9.24 \%$ while that in the foreign operation rises by $14.95 \%$. The MNF's first-period hedge position is 
$h_{0}^{*}=18.49$ and $z_{0}^{*}=-16.24$, which covers $16.89 \%$ of the exchange rate risk exposure. Such deviations in the optimal production and hedging decisions result in a reduction in the expected global domestic currency profit from 40.72 to 39.57 (a drop by $2.82 \%$ ), and a reduction in the expected utility from 241.38 to 235.83 (a drop by $2.30 \%$ ). Thus, it is indeed important for the MNF to take the liquidity constraint into considerations when it forms its hedging strategy.

\section{Conclusions}

In this paper, we have examined the impact of liquidity risk on the behavior of a risk-averse multinational firm (MNF) under exchange rate uncertainty in a two-period dynamic setting. The MNF has operations domiciled in the home country and in a foreign country, each of which produces a single homogeneous good to be sold in the home and foreign markets. To hedge the exchange rate risk, the MNF has access to one-period currency futures and option contracts in each period. We have introduced liquidity risk to the MNF by imposing a liquidity constraint that obliges the MNF to terminate its risk management program in the second period whenever the net loss due to its first-period hedge position exceeds a predetermined threshold level.

The liquidity constrained MNF is shown to demand a positive risk premium on its foreign sales, which creates a wedge between the marginal revenues in the home and foreign markets. In response to the imposition of the liquidity constraint, the MNF optimally sells less (more) and produces more (less) in the foreign (home) country. The liquidity constrained MNF as such receives a lower expected global domestic currency profit and attains a lower expected utility level than in the case when the liquidity constrained is absent. These results are in line with those of Broll and Zilcha (1992) and Lien and Wong (2005). 
When the liquidity constrained MNF has a quadratic utility function, we have shown that the MNF opts for a long currency option position in the first period. Furthermore, we have shown that the MNF under-hedges its exchange rate risk exposure so as to strike a balance between the extent of the exchange rate risk and that of the liquidity risk. These results are consistent with the empirical findings that nonfinancial firms use options quite often (Bodnar, Hayt, and Marston, 1998) and tend to partially hedge their risk exposures (Tufano, 1996; Bodnar, Hayt, and Marston, 1998). The prevalence of liquidity constraints faced by MNFs thus offers a rationale to the hedging role of currency options and the optimality of under-hedging by these firms.

\section{Acknowledgements}

We gratefully acknowledge financial support from a grant provided by the University Grants Committee of the Hong Kong Special Administrative Region, China (Project No. AoE/H-05/99). We would like to thank Donald Lien, Ike Mathur (the editor), and an anonymous referee for their helpful comments and suggestions. The usual disclaimer applies.

\section{Appendix A}

First-order conditions for program (8). Using Leibniz's rule, the first-order conditions for program (8) with respect to $x_{h}, x_{f}, y_{h}, y_{f}, h_{0}$, and $z_{0}$ are respectively given by

$$
\int_{\underline{\varepsilon}_{1}}^{\varepsilon_{1}^{*}} u^{\prime}\left[\pi_{c}^{*}\left(\varepsilon_{1}\right)\right]\left[r_{x}^{\prime}\left(x_{h}^{*}\right)-c_{x}^{\prime}\left(x_{h}^{*}+x_{f}^{*}\right)\right] \mathrm{d} F\left(\varepsilon_{1}\right)
$$




$$
\begin{aligned}
& +\int_{\varepsilon_{1}^{*}}^{\bar{\varepsilon}_{1}} \mathrm{E}_{2}\left\{u^{\prime}\left[\pi_{\ell}^{*}\left(\varepsilon_{1}, \tilde{\varepsilon}_{2}\right)\right]\right\}\left[r_{x}^{\prime}\left(x_{h}^{*}\right)-c_{x}^{\prime}\left(x_{h}^{*}+x_{f}^{*}\right)\right] \mathrm{d} F\left(\varepsilon_{1}\right)=0, \\
& \int_{\underline{\varepsilon}_{1}}^{\varepsilon_{1}^{*}} u^{\prime}\left[\pi_{c}^{*}\left(\varepsilon_{1}\right)\right]\left[\left(e_{0}+\varepsilon_{1}\right) R_{x}^{\prime}\left(x_{f}^{*}\right)-c_{x}^{\prime}\left(x_{h}^{*}+x_{f}^{*}\right)\right] \mathrm{d} F\left(\varepsilon_{1}\right) \\
& +\int_{\varepsilon_{1}^{*}}^{\bar{\varepsilon}_{1}} \mathrm{E}_{2}\left\{u^{\prime}\left[\pi_{\ell}^{*}\left(\varepsilon_{1}, \tilde{\varepsilon}_{2}\right)\right]\left[\left(e_{0}+\varepsilon_{1}+\tilde{\varepsilon}_{2}\right) R_{x}^{\prime}\left(x_{f}^{*}\right)-c_{x}^{\prime}\left(x_{h}^{*}+x_{f}^{*}\right)\right]\right\} \mathrm{d} F\left(\varepsilon_{1}\right)=0, \\
& \int_{\underline{\varepsilon}_{1}}^{\varepsilon_{1}^{*}} u^{\prime}\left[\pi_{c}^{*}\left(\varepsilon_{1}\right)\right]\left[r_{y}^{\prime}\left(y_{h}^{*}\right)-\left(e_{0}+\varepsilon_{1}\right) c_{y}^{\prime}\left(y_{h}^{*}+y_{f}^{*}\right)\right] \mathrm{d} F\left(\varepsilon_{1}\right) \\
& +\int_{\varepsilon_{1}^{*}}^{\bar{\varepsilon}_{1}} \mathrm{E}_{2}\left\{u^{\prime}\left[\pi_{\ell}^{*}\left(\varepsilon_{1}, \tilde{\varepsilon}_{2}\right)\right]\left[r_{y}^{\prime}\left(y_{h}^{*}\right)-\left(e_{0}+\varepsilon_{1}+\tilde{\varepsilon}_{2}\right) c_{y}^{\prime}\left(y_{h}^{*}+y_{f}^{*}\right)\right]\right\} \mathrm{d} F\left(\varepsilon_{1}\right)=0, \\
& \int_{\varepsilon_{1}}^{\varepsilon_{1}^{*}} u^{\prime}\left[\pi_{c}^{*}\left(\varepsilon_{1}\right)\right]\left(e_{0}+\varepsilon_{1}\right)\left[R_{y}^{\prime}\left(y_{f}^{*}\right)-c_{y}^{\prime}\left(y_{h}^{*}+y_{f}^{*}\right)\right] \mathrm{d} F\left(\varepsilon_{1}\right) \\
& +\int_{\varepsilon_{1}^{*}}^{\bar{\varepsilon}_{1}} \mathrm{E}_{2}\left\{u^{\prime}\left[\pi_{\ell}^{*}\left(\varepsilon_{1}, \tilde{\varepsilon}_{2}\right)\right]\left(e_{0}+\varepsilon_{1}+\tilde{\varepsilon}_{2}\right)\right\}\left[R_{y}^{\prime}\left(y_{f}^{*}\right)-c_{y}^{\prime}\left(y_{h}^{*}+y_{f}^{*}\right)\right] \mathrm{d} F\left(\varepsilon_{1}\right)=0, \\
& +\int_{\varepsilon_{1}^{*}}^{\bar{\varepsilon}_{1}} \mathrm{E}_{2}\left\{u^{\prime}\left[\pi_{\ell}^{*}\left(\varepsilon_{1}, \tilde{\varepsilon}_{2}\right)\right]\right\}\left(f_{0}-e_{0}-\varepsilon_{1}\right) \mathrm{d} F\left(\varepsilon_{1}\right)-\phi_{1}=0, \\
& \int_{\varepsilon_{1}}^{\varepsilon_{1}^{*}} u^{\prime}\left[\pi_{c}^{*}\left(\varepsilon_{1}\right)\right]\left(f_{0}-e_{0}-\varepsilon_{1}\right) \mathrm{d} F\left(\varepsilon_{1}\right)
\end{aligned}
$$

and

$$
\begin{aligned}
& \int_{\underline{\varepsilon}_{1}}^{\varepsilon_{1}^{*}} u^{\prime}\left[\pi_{c}^{*}\left(\varepsilon_{1}\right)\right]\left[p_{0}-\max \left(e_{0}+\varepsilon_{1}-s_{0}, 0\right)\right] \mathrm{d} F\left(\varepsilon_{1}\right) \\
& +\int_{\varepsilon_{1}^{*}}^{\bar{\varepsilon}_{1}} \mathrm{E}_{2}\left\{u^{\prime}\left[\pi_{\ell}^{*}\left(\varepsilon_{1}, \tilde{\varepsilon}_{2}\right)\right]\right\}\left[p_{0}-\max \left(e_{0}+\varepsilon_{1}-s_{0}, 0\right)\right] \mathrm{d} F\left(\varepsilon_{1}\right)-\phi_{2}=0,
\end{aligned}
$$

where an asterisk $\left(^{*}\right)$ indicates an optimal level, $\varepsilon_{1}^{*}=\left(k+f_{0} h_{0}^{*}+s_{0} z_{0}^{*}\right) /\left(h_{0}^{*}+z_{0}^{*}\right)-e_{0}$,

$$
\phi_{1}=\left\{u\left[\pi_{c}^{*}\left(\varepsilon_{1}^{*}\right)\right]-\mathrm{E}\left\{u\left[\pi_{\ell}^{*}\left(\varepsilon_{1}^{*}, \tilde{\varepsilon}_{2}\right)\right]\right\}\right\} F^{\prime}\left(\varepsilon_{1}^{*}\right) \frac{k+\left(s_{0}-f_{0}\right) z_{0}^{*}}{\left(h_{0}^{*}+z_{0}^{*}\right)^{2}}
$$


and

$$
\phi_{2}=\left\{u\left[\pi_{c}^{*}\left(\varepsilon_{1}^{*}\right)\right]-\mathrm{E}\left\{u\left[\pi_{\ell}^{*}\left(\varepsilon_{1}^{*}, \tilde{\varepsilon}_{2}\right)\right]\right\}\right\} F^{\prime}\left(\varepsilon_{1}^{*}\right) \frac{k+\left(f_{0}-s_{0}\right) h_{0}^{*}}{\left(h_{0}^{*}+z_{0}^{*}\right)^{2}}
$$

Using Eqs. (6) and (7) and the fact that $\tilde{\varepsilon}_{2}$ has a mean of zero yields $\pi_{c}^{*}\left(\varepsilon_{1}^{*}\right)=$ $\mathrm{E}\left[\pi_{\ell}^{*}\left(\varepsilon_{1}^{*}, \tilde{\varepsilon}_{2}\right)\right]$. It then follows from Jensen's inequality and risk aversion that the righthand of Eq. (A.7) is positive so that $\phi_{1}>0$.

Since $u^{\prime}(\pi)>0$, Eqs. (A.1) and (A.4) reduce to Eqs. (9) and (12), respectively. Multiplying $R_{x}^{\prime}\left(x_{f}^{*}\right)$ to Eq. (A.5) and adding the resulting equation to Eq. yields Eq. (10), where

$$
\theta=\frac{\phi_{1}-\int_{\varepsilon_{1}^{*}}^{\bar{\varepsilon}_{1}} \mathrm{E}_{2}\left\{u^{\prime}\left[\pi_{\ell}^{*}\left(\varepsilon_{1}, \tilde{\varepsilon}_{2}\right)\right] \tilde{\varepsilon}_{2}\right\} \mathrm{d} F\left(\varepsilon_{1}\right)}{\int_{\underline{\varepsilon}_{1}^{*}}^{\varepsilon_{1}^{*}} u^{\prime}\left[\pi_{c}^{*}\left(\varepsilon_{1}\right)\right] \mathrm{d} F\left(\varepsilon_{1}\right)+\int_{\varepsilon_{1}^{*}}^{\bar{\varepsilon}_{1}} \mathrm{E}_{2}\left\{u^{\prime}\left[\pi_{\ell}^{*}\left(\varepsilon_{1}, \tilde{\varepsilon}_{2}\right)\right]\right\} \mathrm{d} F\left(\varepsilon_{1}\right)} .
$$

Multiplying $c_{y}^{\prime}\left(y_{h}^{*}+y_{f}^{*}\right)$ to Eq. (A.5) and subtracting the resulting equation from Eq. (A.3) yields Eq. (11), where $\theta$ is given by Eq. (A.9). Note that $\mathrm{E}\left\{u^{\prime}\left[\pi_{\ell}^{*}\left(\varepsilon_{1}, \tilde{\varepsilon}_{2}\right)\right] \tilde{\varepsilon}_{2}\right\}=$ $\operatorname{Cov}\left\{u^{\prime}\left[\pi_{\ell}^{*}\left(\varepsilon_{1}, \tilde{\varepsilon}_{2}\right)\right], \tilde{\varepsilon}_{2}\right\}$, where $\operatorname{Cov}(\cdot, \cdot)$ is the covariance operator with respect to the cumulative distribution function of $\tilde{\varepsilon}_{2}$. Note also that $\partial u^{\prime}\left[\pi_{\ell}^{*}\left(\varepsilon_{1}, \varepsilon_{2}\right)\right] / \partial \varepsilon_{2}=$ $u^{\prime \prime}\left[\pi_{\ell}^{*}\left(\varepsilon_{1}, \varepsilon_{2}\right)\right]\left[R_{x}\left(x_{f}^{*}\right)+R_{y}\left(y_{f}^{*}\right)-c_{y}\left(y_{h}^{*}+y_{f}^{*}\right)\right]<0$. Thus, we have $\operatorname{Cov}\left\{u^{\prime}\left[\pi_{\ell}^{*}\left(\varepsilon_{1}, \tilde{\varepsilon}_{2}\right)\right], \tilde{\varepsilon}_{2}\right\}<$ 0. Eqs. (A.7) and (A.9) then imply that $\theta>0$.

Proof of Proposition 1. Suppose first that $x_{h}^{*} \leq x_{h}^{0}$. Since $r_{x}^{\prime \prime}\left(x_{h}\right)<0$, we have $r_{x}^{\prime}\left(x_{h}^{*}\right) \geq r_{x}^{\prime}\left(x_{h}^{0}\right)$. Eqs. (9) and (13) then imply that $c_{x}^{\prime}\left(x_{h}^{*}+x_{f}^{*}\right) \geq c_{x}^{\prime}\left(x_{h}^{0}+x_{f}^{0}\right)$. Since $c_{x}^{\prime \prime}(x)>0$ and $x_{h}^{*} \leq x_{h}^{0}$, we must have $x_{f}^{*} \geq x_{f}^{0}$. It then follows from $R_{x}^{\prime \prime}\left(x_{f}\right)<0$ and $\theta>0$ that $\left(f_{0}-\theta\right) R_{x}^{\prime}\left(x_{f}^{*}\right)<f_{0} R_{x}^{\prime}\left(x_{f}^{0}\right)$. But this inequality together with Eqs. (10) and (14) would imply that $c_{x}^{\prime}\left(x_{h}^{*}+x_{f}^{*}\right)<c_{x}^{\prime}\left(x_{h}^{0}+x_{f}^{0}\right)$, a contradiction. Hence, the supposition is not true and we must have $x_{h}^{*}>x_{h}^{0}$. It then follows from $r_{x}^{\prime \prime}\left(x_{h}\right)<0$ that $r_{x}^{\prime}\left(x_{h}^{*}\right)<r_{x}^{\prime}\left(x_{h}^{0}\right)$. Eqs. (9) and (13) thus imply that $c_{x}^{\prime}\left(x_{h}^{*}+x_{f}^{*}\right)<c_{x}^{\prime}\left(x_{h}^{0}+x_{f}^{0}\right)$. Since $c_{x}^{\prime \prime}(x)>0$, we must have $x_{h}^{*}+x_{f}^{*}<x_{h}^{0}+x_{f}^{0}$ and thereby $x_{f}^{*}<x_{f}^{0}$. 
Now, suppose that $y_{f}^{*} \geq y_{f}^{0}$. Since $R_{y}^{\prime \prime}\left(y_{f}\right)<0$, we have $R_{y}^{\prime}\left(y_{f}^{*}\right) \leq R_{y}^{\prime}\left(y_{f}^{0}\right)$. Eqs. (12) and (16) then imply that $c_{y}^{\prime}\left(y_{h}^{*}+y_{f}^{*}\right) \leq c_{y}^{\prime}\left(y_{h}^{0}+y_{f}^{0}\right)$. Since $c_{y}^{\prime \prime}(y)>0$ and $y_{f}^{*} \geq y_{f}^{0}$, we must have $y_{h}^{*} \leq y_{h}^{0}$. It then follows from $r_{y}^{\prime \prime}\left(y_{h}\right)<0$ that $r_{y}^{\prime}\left(y_{h}^{*}\right) \geq r_{y}^{\prime}\left(y_{h}^{0}\right)$. But this inequality together with Eqs. (10) and (14) and $\theta>0$ would imply that $c_{y}^{\prime}\left(y_{h}^{*}+y_{f}^{*}\right)>c_{y}^{\prime}\left(y_{h}^{0}+y_{f}^{0}\right)$, a contradiction. Hence, the supposition is not true and we must have $y_{f}^{*}<y_{f}^{0}$. It then follows from $R_{y}^{\prime \prime}\left(y_{f}\right)<0$ that $R_{y}^{\prime}\left(y_{f}^{*}\right)>R_{y}^{\prime}\left(y_{f}^{0}\right)$. Eqs. (12) and (16) thus imply that $c_{y}^{\prime}\left(y_{h}^{*}+y_{f}^{*}\right)>c_{y}^{\prime}\left(y_{h}^{0}+y_{f}^{0}\right)$. Since $c_{y}^{\prime \prime}(y)>0$, we must have $y_{h}^{*}+y_{f}^{*}>y_{h}^{0}+y_{f}^{0}$ and thereby $y_{h}^{*}>y_{h}^{0}$.

Proof of Proposition 2. Consider the following:

$$
\begin{aligned}
& \mathrm{E}_{1}\left\{\left\{\tilde{\varepsilon}_{1}+v\left[\max \left(e_{0}+\tilde{\varepsilon}_{1}-s_{0}, 0\right)-p_{0}\right]\right\}^{2}\right\} \\
& =\operatorname{Var}_{1}\left(\tilde{\varepsilon}_{1}\right)+2 v \operatorname{Cov}_{1}\left[\tilde{\varepsilon}_{1}, \max \left(e_{0}+\tilde{\varepsilon}_{1}-s_{0}, 0\right)\right]+v^{2} \operatorname{Var}_{1}\left[\max \left(e_{0}+\tilde{\varepsilon}_{1}-s_{0}, 0\right)\right],
\end{aligned}
$$

which is positive for all real values of $v$. Set

$$
v=-\frac{\operatorname{Cov}_{1}\left[\tilde{\varepsilon}_{1}, \max \left(e_{0}+\tilde{\varepsilon}_{1}-s_{0}, 0\right)\right]}{\operatorname{Var}_{1}\left[\max \left(e_{0}+\tilde{\varepsilon}_{1}-s_{0}, 0\right)\right]} .
$$

Substituting Eq. (A.11) into the right-hand side of Eq. (A.10) yields

$$
\operatorname{Var}_{1}\left(\tilde{\varepsilon}_{1}\right)-\frac{\operatorname{Cov}_{1}\left[\tilde{\varepsilon}_{1}, \max \left(e_{0}+\tilde{\varepsilon}_{1}-s_{0}, 0\right)\right]^{2}}{\operatorname{Var}_{1}\left[\max \left(e_{0}+\tilde{\varepsilon}_{1}-s_{0}, 0\right)\right]}>0
$$

Hence, the denominators on the right-hand sides of Eqs. (24) and (25) are positive.

Since $e_{0}+\tilde{\varepsilon}_{1}-s_{0}=\max \left(e_{0}+\tilde{\varepsilon}_{1}-s_{0}, 0\right)-\max \left(s_{0}-e_{0}-\tilde{\varepsilon}_{1}, 0\right)$, we have

$$
\begin{aligned}
& \operatorname{Cov}_{1}\left[\tilde{\varepsilon}_{1}, \max \left(e_{0}+\tilde{\varepsilon}_{1}-s_{0}, 0\right)\right]-\operatorname{Var}_{1}\left[\max \left(e_{0}+\tilde{\varepsilon}_{1}-s_{0}, 0\right)\right] \\
& =-\operatorname{Cov}_{1}\left[\max \left(e_{0}+\tilde{\varepsilon}_{1}-s_{0}, 0\right), \max \left(s_{0}-e_{0}-\tilde{\varepsilon}_{1}, 0\right)\right]
\end{aligned}
$$




$$
\begin{aligned}
= & -\mathrm{E}_{1}\left[\max \left(e_{0}+\tilde{\varepsilon}_{1}-s_{0}, 0\right) \max \left(s_{0}-e_{0}-\tilde{\varepsilon}_{1}, 0\right)\right] \\
& +\mathrm{E}_{1}\left[\max \left(e_{0}+\tilde{\varepsilon}_{1}-s_{0}, 0\right)\right] \mathrm{E}_{1}\left[\max \left(s_{0}-e_{0}-\tilde{\varepsilon}_{1}, 0\right)\right] \\
= & \mathrm{E}_{1}\left[\max \left(e_{0}+\tilde{\varepsilon}_{1}-s_{0}, 0\right)\right] \mathrm{E}_{1}\left[\max \left(s_{0}-e_{0}-\tilde{\varepsilon}_{1}, 0\right)\right]>0 .
\end{aligned}
$$

Subtracting Eq. (20) from Eq. (21) yields

$$
\psi_{2}-\psi_{1}=\frac{1}{2} \mathrm{E}_{2}\left(\tilde{\varepsilon}_{2}^{2}\right)\left[R_{x}\left(x_{f}^{*}\right)+R_{y}\left(y_{f}^{*}\right)-c_{y}\left(y_{h}^{*}+y_{f}^{*}\right)\right]^{2} F^{\prime}\left(\varepsilon_{1}^{*}\right) \frac{e_{0}-s_{0}}{h_{0}^{*}+z_{0}^{*}}
$$

The numerator on the right-hand side of Eq. (24) can be written as

$$
\begin{aligned}
& \psi_{2}\left\{\operatorname{Cov}_{1}\left[\tilde{\varepsilon}_{1}, \max \left(e_{0}+\tilde{\varepsilon}_{1}-s_{0}, 0\right)\right]-\operatorname{Var}_{1}\left[\max \left(e_{0}+\tilde{\varepsilon}_{1}-s_{0}, 0\right)\right]\right\} \\
& +\left(\psi_{2}-\psi_{1}\right) \operatorname{Var}_{1}\left[\max \left(e_{0}+\tilde{\varepsilon}_{1}-s_{0}, 0\right)\right]
\end{aligned}
$$

which is strictly positive if $s_{0} \leq e_{0}$, as is evident from Eqs. (A.13) and (A.14). By continuity, it then follows form Eq. (24) that $h_{0}^{*}>R_{x}\left(x_{f}^{*}\right)+R_{y}\left(y_{f}^{*}\right)-c_{y}\left(y_{h}^{*}+y_{f}^{*}\right)$ if the first-period currency call options are not too out of the money.

Since $e_{0}+\tilde{\varepsilon}_{1}-s_{0}=\max \left(e_{0}+\tilde{\varepsilon}_{1}-s_{0}, 0\right)-\max \left(s_{0}-e_{0}-\tilde{\varepsilon}_{1}, 0\right)$, we have

$$
\begin{aligned}
& \operatorname{Var}_{1}\left(\tilde{\varepsilon}_{1}\right)-\operatorname{Cov}_{1}\left[\tilde{\varepsilon}_{1}, \max \left(e_{0}+\tilde{\varepsilon}_{1}-s_{0}, 0\right)\right] \\
& =-\operatorname{Cov}_{1}\left[\tilde{\varepsilon}_{1}, \max \left(s_{0}-e_{0}-\tilde{\varepsilon}_{1}, 0\right)\right]>0
\end{aligned}
$$

The numerator on the right-hand side of Eq. (25) can be written as

$$
\psi_{1}\left\{\operatorname{Cov}_{1}\left[\tilde{\varepsilon}_{1}, \max \left(e_{0}+\tilde{\varepsilon}_{1}-s_{0}, 0\right)\right]-\operatorname{Var}_{1}\left(\tilde{\varepsilon}_{1}\right)\right\}-\left(\psi_{2}-\psi_{1}\right) \operatorname{Var}_{1}\left(\tilde{\varepsilon}_{1}\right),
$$


which is strictly negative if $s_{0} \leq e_{0}$, as is evident from Eqs. (A.15) and (A.14). By continuity, it then follows form Eq. (25) that $z_{0}^{*}<0$ if the first-period currency call options are not too out of the money.

Finally, we add Eqs. (24) and (25) to yield

$$
\begin{aligned}
& h_{0}^{*}+z_{0}^{*}=R_{x}\left(x_{f}^{*}\right)+R_{y}\left(y_{f}^{*}\right)-c_{y}\left(y_{h}^{*}+y_{f}^{*}\right) \\
& +\frac{\left(\psi_{1}+\psi_{2}\right) \operatorname{Cov}_{1}\left[\tilde{\varepsilon}_{1}, \max \left(e_{0}+\tilde{\varepsilon}_{1}-s_{0}, 0\right)\right]-\psi_{1} \operatorname{Var}_{1}\left[\max \left(e_{0}+\tilde{\varepsilon}_{1}-s_{0}, 0\right)\right]-\psi_{2} \operatorname{Var}_{1}\left(\tilde{\varepsilon}_{1}\right)}{\operatorname{Var}_{1}\left(\tilde{\varepsilon}_{1}\right) \operatorname{Var}\left[\max \left(e_{0}+\tilde{\varepsilon}_{1}-s_{0}, 0\right)\right]-\operatorname{Cov}_{1}\left[\tilde{\varepsilon}_{1}, \max \left(e_{0}+\tilde{\varepsilon}_{1}-s_{0}, 0\right)\right]^{2}} .
\end{aligned}
$$

Using Eqs. (A.13) and (A.15), we can write the numerator on the right-hand side of Eq. (A.16) as

$$
\begin{aligned}
& \psi_{2} \operatorname{Cov}_{1}\left[\tilde{\varepsilon}_{1}, \max \left(s_{0}-e_{0}-\tilde{\varepsilon}_{1}, 0\right)\right] \\
& -\psi_{1} \operatorname{Cov}_{1}\left[\max \left(e_{0}+\tilde{\varepsilon}_{1}-s_{0}, 0\right), \max \left(s_{0}-e_{0}-\tilde{\varepsilon}_{1}, 0\right)\right] .
\end{aligned}
$$

Since $e_{0}+\tilde{\varepsilon}_{1}-s_{0}=\max \left(e_{0}+\tilde{\varepsilon}_{1}-s_{0}, 0\right)-\max \left(s_{0}-e_{0}-\tilde{\varepsilon}_{1}, 0\right)$, we can write the above expression as

$$
\begin{aligned}
& \left(\psi_{2}-\psi_{1}\right) \operatorname{Cov}_{1}\left[\max \left(e_{0}+\tilde{\varepsilon}_{1}-s_{0}, 0\right), \max \left(s_{0}-e_{0}-\tilde{\varepsilon}_{1}, 0\right)\right] \\
& -\psi_{2} \operatorname{Var}_{1}\left[\max \left(s_{0}-e_{0}-\tilde{\varepsilon}_{1}, 0\right)\right] \\
& =\left(\psi_{1}-\psi_{2}\right) \mathrm{E}_{1}\left[\max \left(e_{0}+\tilde{\varepsilon}_{1}-s_{0}, 0\right)\right] \mathrm{E}_{1}\left[\max \left(s_{0}-e_{0}-\tilde{\varepsilon}_{1}, 0\right)\right] \\
& -\psi_{2} \operatorname{Var}_{1}\left[\max \left(s_{0}-e_{0}-\tilde{\varepsilon}_{1}, 0\right)\right],
\end{aligned}
$$


which is strictly negative if $s_{0} \leq e_{0}$, as is evident from Eq. (A.14). By continuity, it then follows form Eq. (A.16) that $h_{0}^{*}+z_{0}^{*}<R_{x}\left(x_{f}^{*}\right)+R_{y}\left(y_{f}^{*}\right)-c_{y}\left(y_{h}^{*}+y_{f}^{*}\right)$ if the first-period currency call options are not too out of the money.

\section{References}

Adam-Müller, A.F.A., 1997. Export and hedging decisions under revenue and exchange rate risk: a note. European Economic Review 41, 1421-1426.

Bodnar, G.M., Hayt, G.S., Marston, R.C., 1998. 1998 Wharton survey of financial risk management by US non-financial firms. Financial Management 27, 70-91.

Broll, U., Zilcha, I., 1992. Exchange rate uncertainty, futures markets and the multinational firm. European Economic Review 36, 815-826.

Committee on Payment and Settlement Systems, 1998. OTC derivatives: Settlement procedures and counterparty risk management. Bank for International Settlements, Basel, Switzerland.

Culp, C.L., Hanke, S.H., 1994. Derivative dingbats. International Economy 8, 12.

Culp, C.L., Miller, M.H., 1995. Metallgesellschaft and the economics of synthetic storage. Journal of Applied Corporate Finance 7, 62-76.

Katz, E., Paroush, J., 1979. The effect of forward markets on exporting firms. Economics Letters 4, 272-274.

Kawai, M., Zilcha, I., 1986. International trade with forward-futures markets under exchange rate and price uncertainty. Journal of International Economics 20, 83-98. 
Kimball, M.S., 1990. Precautionary saving in the small and in the large. Econometrica $58,53-73$.

Kimball, M.S., 1993. Standard risk aversion. Econometrica 61, 589-611.

Lien, D., Wong, K.P., 2005. Multinationals and futures hedging under liquidity constraints. Global Finance Journal 16, 210-220.

Sercu, P., Uppal, R., 1995. International Financial Markets and the Firm. SouthWestern College Publishing, Cincinnati.

Stulz, R.M., 1996. Rethinking risk management. Journal of Applied Corporate Finance $9,8-24$.

Tufano, P., 1996. Who manages risk? An empirical examination of risk management practices in the gold mining industry. Journal of Finance 51, 1097-1137.

Wong, K.P., 2003a. Export flexibility and currency hedging. International Economic Review 44, 1295-1312.

Wong, K.P., 2003b. Currency hedging with options and futures. European Economic Review 47, 833-839.

Wong, K.P., 2004. Hedging, liquidity, and the competitive firm under price uncertainty. Journal of Futures Markets 24, 697-706.

Wong, K.P., 2006. Foreign direct investment and forward hedging. Journal of Multinational Financial Management 16, 459-474. 